\title{
Hospedeiros Alternativos de Xanthomonas campestris pv. viticola
}

\author{
Ana Rosa Peixoto ${ }^{1}$, Rosa L.R. Mariano², José Osmã T. Moreira ${ }^{1}$ \& Ivanise O. Viana² \\ ${ }^{1}$ Departamento de Tecnologia e Ciências Sociais, Universidade do Estado da Bahia, Campus III, CEP 48900-000, Juazeiro, \\ BA, Brasil, e-mail: anarpeixoto@gmail.com; ${ }^{2}$ Departamento de Agronomia, Universidade Federal Rural de Pernambuco, \\ Av. Dom Manoel de Medeiros, s/n, Dois Irmãos, CEP 52171-900, Recife, PE, Brasil, e-mail: rmariano@truenet.com.br
}

Autor para correspondência: Rosa L.R. Mariano

PEIXOTO, A.R., MARIANO, R.L.R., MOREIRA, J.O.T. \& VIANA, I.O. Hospedeiros alternativos de Xanthomonas campestris pv. viticola. Fitopatologia Brasileira 32:161-164. 2007.

\begin{abstract}
RESUMO
Xanthomonas campestris pv. viticola $(\mathrm{Xcv})$, que causa o cancro bacteriano da videira, sobrevive em plantas infectadas, epifiticamente em órgãos da parte aérea e pode ser veiculada em mudas e/ou bacelos infectados. O trabalho teve como objetivo investigar possíveis hospedeiros alternativos do patógeno, visando fornecer subsídios para o manejo da doença. A partir das plantas invasoras Alternanthera tenella, Amaranthus sp., Glycine sp. e Senna obtusifolia com sintomas similares aos do cancro bacteriano da videira, coletadas em parreirais de Juazeiro e Petrolina, no Submédio São Francisco, foram isoladas bactérias semelhantes a Xcv. No entanto, nenhuma bactéria foi isolada de plantas de Commelina benghalensis e Azadirachta indica com sintomas semelhantes. A patogenicidade dos isolados bacterianos obtidos foi confirmada em plantas de A. tenella, Amaranthus sp., Glycine sp., S. obtusifolia e em mudas de videira cv. Red Globe, em condições de casa de vegetação. As plantas invasoras Chamaesyce hirta, Dactyloctenium aegyptium, Eragrostis pilosa e Pilea sp., inoculadas artificialmente com os isolados Xcv1 e UnB1216, também desenvolveram sintomas típicos do cancro bacteriano.
\end{abstract}

Palavras-chave adicionais: Vitis sp., cancro bacteriano da videira, plantas invasoras.

\begin{abstract}
Alternative hosts of Xanthomonas campestris pv. viticola

Xanthomonas campestris pv. viticola (Xcv), which causes the bacterial canker of grapevine, survives in infected plants as an epiphyte on aerial plant parts and may be carried in infected transplants and/or cuttings. This study was performed to investigate putative alternative hosts of the pathogen, aiming to find support for disease management. Bacteria similar to Xcv were isolated from the weeds Alternanthera tenella, Amaranthus sp., Glycine sp. and Senna obtusifolia showing canker-like symptoms and collected in vineyards of Juazeiro and Petrolina at the Submédio São Francisco. No bacteria were isolated from Commelina benghalensis and Azadirachta indica showing similar symptoms. The pathogenicity of the isolates was confirmed in plants of A. tenella, Amaranthus sp., Glycine sp., S. obtusifolia and grapevine cv. Red Globe, under greenhouse conditions. The weeds Chamaesyce hirta, Dactyloctenium aegyptium, Eragrostis pilosa and Pilea sp., artificially inoculated with strains Xcv1 and UnB1216, also developed typical symptoms of bacterial canker.
\end{abstract}

Additional keywords: Vitis sp., bacterial canker of grapevine, weeds.

O cancro bacteriano da videira (Vitis sp.) é causado pela bactéria Xanthomonas campestris pv. viticola (Nayudu) Dye (Xcv) que sobrevive de um ciclo para outro em plantas infectadas ou epifíticamente em órgãos da parte aérea, em condições de alta umidade e temperatura (Araujo, 2001). A bactéria pode ser introduzida em parreirais veiculada em mudas e/ou bacelos infectados, que irão originar plantas doentes. A doença foi, provavelmente, introduzida no Brasil em material de plantio contaminado proveniente da Índia ou de outros hospedeiros potenciais como mangueira (Mangifera indica L.) e nim (Azadirachta indica A. Juss) (Trindade et al., 2005), embora apenas o nim (Desai et al.,1966; Nayudu, 1972) e Phyllanthus maderaspatensis L. (Nayudu, 1972) tenham sido relatados como hospedeiros naturais de Xcv naquele país. No Brasil, inoculações artificiais com Xcv produziram sintomas em aroeira (Schinus

Parte da Tese de Doutorado do primeiro autor. Universidade Federal Rural de Pernambuco. Recife PE. 2005. terebinthifolius Raddi), cajá-manga (Spondias dulcis G. Forst.), cajueiro (Anacardium occidentale L.), mangueira, umbuzeiro (Spondias tuberosa Arruda) (Araujo et al., 1999) e nim (Araujo et al., 1999; Malavolta \& Almeida, 2000; Nascimento et al., 2001).

Considerando que o controle químico é ineficiente e a erradicação inviável, medidas preventivas são as mais recomendadas, destacando-se: poda de ramos doentes, eliminação de plantas severamente atacadas, desinfestação de ferramentas de poda, desbaste e raleio, queima de restos de cultura (Lopes \& Nascimento, 2004) e eliminação de plantas invasoras, que são possíveis hospedeiros alternativos do patógeno (Lima, 2000).

O objetivo do trabalho foi verificar a ocorrência do cancro bacteriano em diferentes espécies de plantas invasoras, em campo e por inoculação artificial, visando fornecer subsídios para o manejo de hospedeiros alternativos do patógeno em áreas de produção agrícola.

Em Petrolina e Juazeiro, no Submédio São Francisco, 
em parreirais infectados com o cancro bacteriano foram observados sintomas semelhantes aos desta doença nas seguintes plantas invasoras: apaga-fogo, periquito ou alecrim (Alternanthera tenella Colla), caruru ou bredo (Amaranthus sp.), soja perene (Glycine sp.), fedegoso (Senna obtusifolia (L.) H.S. Irwin \& Barneby), trapoeraba (Commelina benghalensis L.) e nim. Essas plantas foram coletadas, herborizadas em papel jornal e levadas ao Laboratório de Fitobacteriologia da Universidade Federal Rural de Pernambuco, Recife PE, para isolamento. Os tecidos infectados foram lavados com água e sabão, seccionados em fragmentos de $2 \mathrm{~mm}$ de comprimento, desinfestados em série de álcool etílico a 50\%, hipoclorito de sódio a 1,5\%, água destilada e esterilizada (ADE) por duas vezes, macerados em ADE e deixados em repouso por 20 min. A suspensão foi plaqueada pelo método de estrias em meio semi-seletivo NYDAM (extrato de carne 3, peptona 5, glicose 10, extrato de levedura 5, ágar 18 e ampicilina 0,1 g/L) (Nascimento et al., 2006). Os isolados foram preservados em ADE e mantidos em meio NYDA para os testes de patogenicidade.

Para os testes de patogenicidade, sementes de $A$. tenella, Amaranthus sp., Glycine sp. e S. obtusifolia foram semeadas em recipientes plásticos de $400 \mathrm{~mL}$, contendo solo desinfestado com brometo de metila. Aos 20 dias, 15 plantas de cada hospedeiro, assim como de mudas de videira cv. Red Globe com 90 dias de idade, foram inoculadas utilizandose duas técnicas: fricção com gaze e picada no caule. $\mathrm{Na}$ primeira, compressas de gaze dupla umedecidas com 0,5 $\mathrm{mL}$ da suspensão bacteriana foram levemente friccionadas em ambas as superfícies da folha. Na segunda técnica, cinco picadas foram feitas com estilete no caule, seguindo-se a deposição de células bacterianas com 48 h utilizando alça de platina, cobertura com algodão umedecido em ADE, envolvendo-se o caule com papel alumínio (Nascimento et al., 1998). A concentração das suspensões bacterianas em ADE foi ajustada para $\mathrm{A}_{570}=0,4\left(10^{8} \mathrm{UFC} \mathrm{mL}^{-1}\right)$, adicionandose, posteriormente, Tween 20 para concentração final de
0,05\%. As plantas foram submetidas ao pré e pós-tratamento em câmara úmida por 48 h. As plantas dos tratamentos testemunha, por sua vez, foram tratadas apenas com ADE. Todas as plantas foram mantidas em casa de vegetação, a temperatura de $30 \pm 2{ }^{\circ} \mathrm{C}$ com irrigação diária.

Os isolados Xcv1 (Coleção de Culturas do Laboratório de Fitobacteriologia, UFRPE) e UnB 1216 (Coleção de Culturas do Laboratório de Fitopatologia, UnB) foram também inoculados por picada no caule das seguintes plantas invasoras: brilhantina (Pilea sp.), burra-leiteira (Chamaesyce hirta (L.) Millsp.), capim barbicha-de-leão (Eragrostis pilosa P. Beauv.) e capim mão-de-sapo [Dactyloctenium aegyptium (L.) P. Beauv.], em média de cinco plantas por espécie. Estas plantas haviam vegetado espontaneamente no solo ao redor das mudas de videira provenientes da Estação Experimental da Embrapa Semi-Árido em Mandacaru, Juazeiro, BA e têm ocorrência comum nos estados da Bahia e Pernambuco (Lorenzi, 1991).

Das plantas de A. tenella, Amaranthus sp., Glycine sp. e $S$. obtusifolia (Tabela 1, Figura 1A-B-C-D-E) com sintomas do cancro foram isoladas em meio semi-seletivo NYDAM, populações de bactérias semelhantes à Xcv, apresentando colônias arredondadas, coloração esbranquiçada, brilhantes, com bordos lisos, células em forma de bastonetes, Gramnegativas. Por outro lado, isolados bacterianos não foram obtidos de $C$. benghalensis e $A$. indica com sintomas similares (Tabela 1, Figura 2). Este último resultado discorda de Desai et al. (1966) que relataram o nim como hospedeiro natural de Xcv e de Nayudu (1972) que aventou a possibilidade de que o nim e $P$. maderaspatensis atuassem como fontes adicionais de inóculo, principalmente em áreas onde a videira estivesse sendo introduzida. Além disso, o nim foi hospedeiro suscetível em diversas inoculações artificiais realizadas no Brasil (Araujo et al., 1999; Malavolta \& Almeida, 2000; Nascimento et al., 2001) apesar de não apresentar sintomas quando inoculados por Chand \& Kishun (1990).

Oito dias após a inoculação com os isolados

TABELA 1 - Plantas invasoras e interação com Xanthomonas campestris pv. viticola

\begin{tabular}{lccccc}
\hline \hline Espécie (Nome comum) & Local & $\begin{array}{c}\text { Sintomas } \\
\text { em campo }\end{array}$ & $\begin{array}{c}\text { Isolamento } \\
\text { de Xcv }\end{array}$ & \multicolumn{2}{c}{ Patogenicidade } \\
\cline { 5 - 6 } & & Espécie & videira \\
\hline Alternanthera tenella (apaga-fogo, periquito, alecrim) & Petrolina & + & + & + & + \\
Amaranthus sp. (caruru, bredo) & Petrolina & + & + & + & + \\
Glycine sp. (soja perene) & Petrolina & + & + & + & + \\
Senna obtusifolia (fedegoso) & Juazeiro & + & + & + & + \\
& Petrolina & & & & \\
Pilea sp. (Brilhantina) & -1 & - & $\mathrm{np}$ & $+^{2}$ & + \\
Chamaesyce hirta (burra-leiteira) & -1 & - & $\mathrm{np}$ & $+^{2}$ & + \\
Eragrostis pilosa (capim barbicha-de-leão) & -1 & - & $\mathrm{np}$ & $+^{2}$ & + \\
Dactyloctenium aegyptium (capim mão-de-sapo) & -1 & - & $\mathrm{np}$ & $++^{2}$ & + \\
Commelina benghalensis (trapoeraba) & Petrolina & + & - & $\mathrm{np}$ & $\mathrm{np}$ \\
Azadirachta indica (nim) & Petrolina & + & - & $\mathrm{np}$ & $\mathrm{np}$ \\
\hline
\end{tabular}

${ }^{1}$ Plantas invasoras que vegetaram espontaneamente no solo ao redor de mudas de videira provenientes de Mandacaru, BA. $\mathrm{np}=$ não pertinente

${ }^{2}$ Teste de patogenicidade em casa de vegetação com isolados Xcv1 e UnB1216 

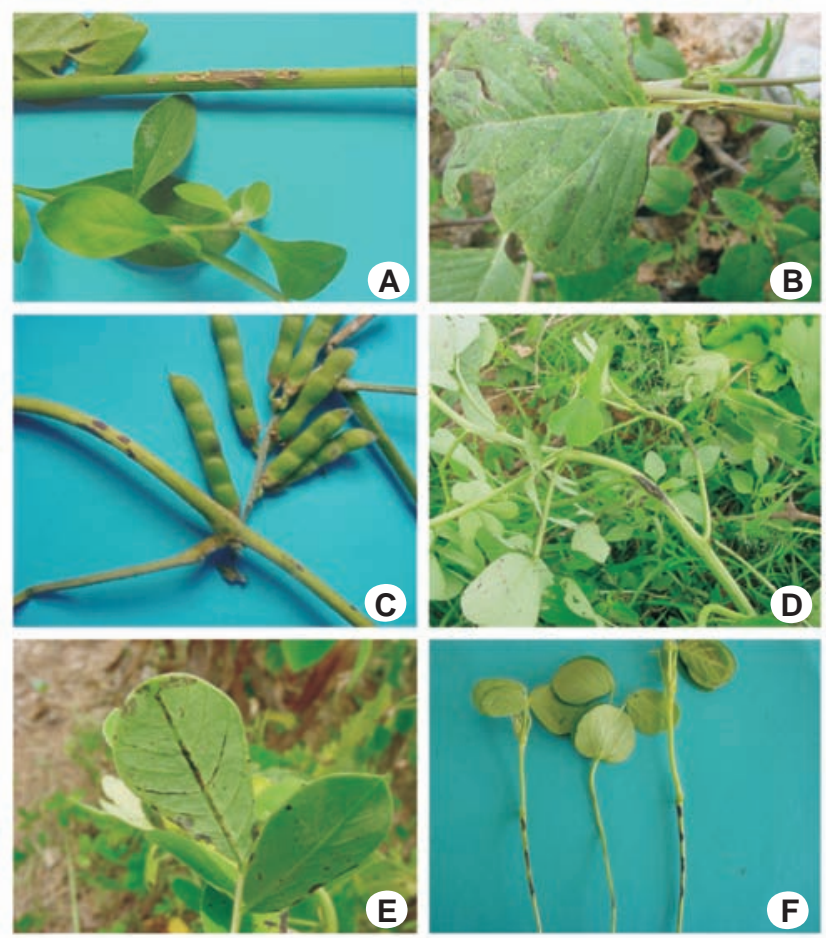

FIG. 1 - Plantas invasoras hospedeiras de Xanthomonas campestris pv. viticola. A. Sintomas naturais de cancro na haste em Alternanthera tenella, B. Amaranthus sp.; C. Glycine sp.; D. Senna obtusifolia; E. Sintoma natural de cancro na nervura da folha em S. obtusifolia; F. Sintomas em S. obtusifolia inoculada artificialmente.
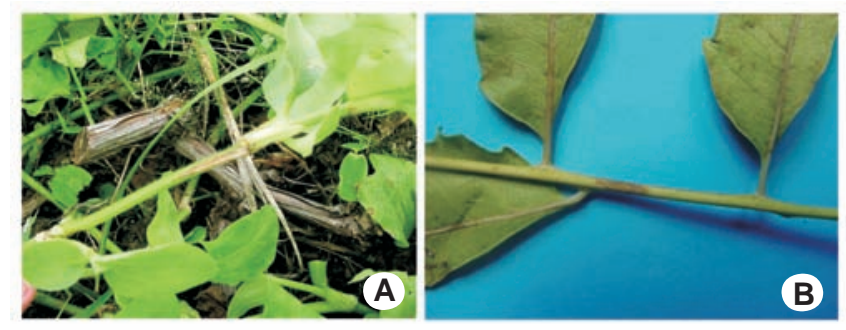

FIG. 2 - Plantas de Commelina benghalensis (A) e Azadirachta indica (B) coletadas em/ou próximas a parreirais com sintomas de cancro bacteriano da videira e das quais não foi possível isolar Xanthomonas campestris pv. viticola.

bacterianos obtidos, tanto as plantas invasoras (Tabela 1, Figura 1F) quanto a videira (Tabela 1) apresentaram sintomas típicos do cancro bacteriano, completando-se os postulados de Koch pelo reisolamento de Xcv em meio NYDAM. Além disso, os isolados de Xcv obtidos de $A$. tenella e $S$. obtusifolia apresentaram perfil de RAPD semelhante aos obtidos de videira (dados não publicados).

Nas plantas invasoras Pilea sp., C. hirta, E. pilosa e D. aegyptium, inoculadas com Xcv1 e Unb 1216, foram observados sintomas do cancro bacteriano após oito dias (Tabela 1). Araujo et al. (1999) e Nascimento et al. (2001) também relataram a patogenicidade de Xcv à mangueira, cajueiro, umbuzeiro, cajá-manga e aroeira quando inoculados artificialmente.

A ampliação do círculo de hospedeiros de Xcv é importante no contexto do manejo da doença em relação à infestação do parreiral por plantas invasoras. Uma das medidas de controle cultural recomendadas para o cancro bacteriano da videira é a remoção de todo material proveniente de podas das videiras infectadas e posterior incineração. No entanto, a partir da confirmação da infecção natural das espécies $A$. tenella, Amaranthus sp., Glycine sp. e $S$. obtusifolia por Xcv, recomenda-se, adicionalmente, a erradicação das mesmas das áreas de plantio para evitar o aumento de fontes de inóculo nos parreirais.

\section{AGRADECIMENTOS}

Ana Rosa Peixoto registra agradecimentos ao PICDT/CAPES/UNEB, Rosa de Lima Ramos Mariano ao Conselho Nacional de Desenvolvimento Científico CNPq pela concessão de bolsas.

\section{REFERÊNCIAS BIBLIOGRÁFICAS}

ARAUJO, J.S.P. Perfil epidemiológico e subsídios para o controle de Xanthomonas campestris pv. viticola (Nayudu) Dye, agente do cancro bacteriano da videira (Vitis vinifera) no Brasil. Tese de Doutorado. Rio de Janeiro RJ. Universidade Federal Rural do Rio de Janeiro. 2001.

ARAUJO, J.S.P., ROBBS, C.F. \& MACIEL, G.F. Novos hospedeiros alternativos de Xanthomonas campestris pv. viticola no Brasil. Summa Phytopathologica 25:23. 1999. (Resumo)

CHAND, R. \& KISHUN, R. Outbreak of grapevine bacterial canker disease in India. Vitis 29:183-188. 1990.

DESAI, S.G., GANDHI, A.B., PATEL, M.K. \& KOTASTHANAE, W.V. A new bacterial leaf-spot and blight of Azadirachta indica A. Juss. Indian Phytopathology 19:322-323. 1966.

LIMA, M.F. Cancro bacteriano da videira causado por Xanthomonas campestris pv. viticola: epidemiologia e manejo. Circular Técnica, 54. Petrolina PE. EMBRAPA Semi-Árido. 2000.

LOPES, D.B. \& NASCIMENTO, A.R.P. Uva: Risco duplo. Cultivar HF 27:26-27. 2004.

LORENZI, H. Plantas daninhas do Brasil: Terrestres, aquáticas, parasitas, tóxicas e medicinais. Nova Odessa. Editora Plantarum. 1991.

MALAVOLTA, V.M.A. \& ALMEIDA, I.M.G. Patogenicidade de Xanthomonas campestris pv. viticola em neem. Summa Phytopathologica 26:129. 2000. (Resumo)

NASCIMENTO, A.R.P., GARZIERA, F., TAVARES, S.H. \& MARIANO, R.L.R. Avaliação de patogenicidade da bactéria da necrose em videiras (Vitis spp.). Fitopatologia Brasileira 23:213. 1998. (Resumo) 
NASCIMENTO, A.R.P., MARIANO, R.L.R. \& VIANA, I.O. Meio semi-seletivo para isolamento de Xanthomonas campestris pv. viticola. Ciência Rural 36:1317-1320. 2006.

NASCIMENTO, A.R.P., SILVA, V.A.V., FACCIOLI, I., MONTEIRO, L. \& CASTRO, G.S. Azadirachta indica-hospedeiro alternativo de Xanthomonas campestris pv. viticola, no Submédio São Francisco. Fitopatologia Brasileira 26:282. 2001. (Resumo)
NAYUDU, M.V. Pseudomonas viticola sp. nov., incitant of a new bacterial disease of grape vine. Phytopathologishe Zeitschrift 73:183-186. 1972.

TRINDADE, L.C., LIMA, M.F. \& FERREIRA, M.A.S.V. Molecular characterization of Brazilian strains of Xanthomonas campestris pv. viticola by rep-PCR fingerprinting. Fitopatologia Brasileira 30:46-54. 2005. 